\title{
Two or Three Consecutive Days Albendazole Treatment Has Better Efficacy than Single-Dose Albendazole Treatment for Trichuriasis
}

\author{
Dina Evalina Gultom*, Muhammad Ali, Ayodhia Pitaloka Pasaribu, Syahril Pasaribu \\ Department of Paediatrics, Faculty of Medicine, Universitas Sumatera Utara, Jl. Dr. Mansyur No.5, Medan, Indonesia \\ *Corresponding author. E-mail: dinagultom64@yahoo.com
}

Received date: Jul 18, 2019; Revised date: Nov 18, 2019; Accepted date: Dec 4, 2019

\section{Abstract}

B ACKGROUND: Soil-transmitted helminth (STH) infection is endemic in Indonesia. Singledose albendazole is routinely used to control STH infections. Some studies found that repeated-dose of albendazole showed better efficacy. There is no study in Indonesia to compare single-dose and repeated-dose albendazole for against STH infections.

METHODS: A randomized, open clinical trial was conducted in July-September 2018 among primary school children. Stool samples were collected before treatment and on day $7,14,21$, and 28 after treatment then stained using the Kato-Katz method. Group I received three consecutive days, group II received two consecutive days, and Group III received single-dose of albendazole. Cure rate (CR) and egg reduction rate (ERR) were compared using Chi-square tests, and eggs per gram (EPG) was compared using the Kruskal Wallis test $(p<0.05)$.

\section{Introduction}

The soil-transmitted helminth (STH) is a group of parasitic nematode worms causing human infection through contact with parasite egg/larvae that thrive in the warm and moist soil of the world's tropical/subtropical countries.(1) The types of STH worms are roundworms (Ascaris lumbricoides), whip worms (Trichuris trichiura), hookworms (Ancylostoma duodenale and Necator americanus), and threadworms (Strongyloides stercoralis).(1,2) An individual, especially a child, is often found infected roundworms, whipworms,
RESULTS: One hundred ninety-five subjects enrolled and divided into 65 subjects in each group. The CR and ERR of trichuriasis after three consecutive days (79.5\% and 97.4\%) and two consecutive days regimen $(70.3 \%$ and $91.9 \%)$ were higher than single-dose regimen $(32.2 \%$ and $74.6 \%)$ with $p<0.001$, but not for ascariasis or hookworm infection. The highest efficacy was found in three consecutive days regimen group. Trichuris trichiura EPG was significantly different among the three groups on day 7, 14, 21, and 28 after treatment $(p<0.001)$.

CONCLUSION: Three and two consecutive days albendazole have better efficacy than single-dose of albendazole for trichuriasis, but not for ascariasis or hookworm infection. Two consecutive days albendazole is better choice for treating trichuriasis with more adherence and less side effect than three consecutive days regimen.

KEYWORDS: soil-transmitted helminth infection, albendazole, single-dose, repeated-dose

Indones Biomed J. 2020; 12(1): 45-50

and hookworms in the same time. It is estimated that approximately one-third of the world's population suffers from these three types of worms in the same time.(3)

The intensity of STH infection is a major factor in understanding STH morbidity. Although mild infections are often asymptomatic, severe infection can disrupt physical growth, immunity, learning ability, and causing micronutrient deficiencies (iron deficiency anemia) leading to poor performance and often absent from school. $(1,4,5)$ The World Health Organization (WHO) has arranged a global strategy to control STH infection morbidity by modern chemotherapy (anthelmintic) for high-risk 
populations, especially school-aged children.(6-8) Orally single-dose of $400-\mathrm{mg}$ albendazole is a recommended anthelmintic for adults and children above the age of two years.(8)

The survey in Indonesia in 2009 showed that $31.8 \%$ of primary school children suffered from STH infections, whereas the prevalence of STH infection in Indonesia in 2015 was almost the same with the range $20 \%-86 \%$ with an average of $30 \% .(8,9)$ Study in Suka Village, North Sumatera, Indonesia in 2016 found the prevalence was $34.4 \%$.(10) The high transmission of ascariasis and trichuriasis are very related to soil contamination by feces containing worm eggs. (11) However, this condition also raises questions about the efficacy of single-dose of albendazole in Indonesia.

Several studies to compare the efficacy of singledose and repeated-dose of albendazole for STH infection have been carried out in several countries. A randomized controlled trial in Gabon in 2014 resulted that the cure rate (CR) and egg reduction rate (ERR) of single-dose of albendazole was $85 \%$ for against ascariasis, whereas two consecutive day albendazole was needed for hookworm infections. The three consecutive day's albendazole was not effective to cure trichuriasis but can reduce the number of eggs to $90.6 \%$.(12) However, there has been no study comparing the efficacy of repeated-dose of albendazole against STH infection in Indonesia. It is important to know which albendazole regimen has better efficacy for treating STH infection in Indonesia.

\section{Methods}

The study was randomized, opened, clinical trial to investigate the efficacy of three consecutive days, two consecutive days and single-dose of albendazole among primary school children in Batubara districts, North Sumatera, Indonesia. Three primary schools served this population. The study was conducted from July to September 2018. The inclusion criteria were children aged 6 to 12 years, one or a combination of STH (A. lumbricoides, $T$. trichiura or hookworms) eggs were found from Kato-Katz methods stool examination and did not consume any anthelmintic for one month before and during the study. Children that were not following research procedures, such as not collecting stool samples or refusing to take anthelmintic were excluded from this study. The health research ethical committee number 58/TGL/KEPK FK USU-RSUP HAM/2018 was obtained from the Medical Faculty of Universitas Sumatera Utara.
All participants who fulfilled the inclusion criteria were enrolled in this study after their parents or legal guardians giving consent. A target sample size of 63 subjects each group was set using hypothesis test formula for different proportions of independent data. The characteristics of data participant were collected through questionnaires. Participants were provided with a stool container and instructed to collect fresh stool. Stool samples were examined using the Kato-Katz method by an experienced laboratory technician who was blinded to the assigned drug regimen. The intensity of infection was evaluated by egg loads for $A$. lumbricoides, T. trichiura, and hookworm.

All participants were simple randomly allocated using a computerized system into three regimen groups; three consecutive days group, two consecutive days group, and single-dose group. These regimens consisted of treatment with a 400-mg albendazole tablet (Holi Pharma, Bandung, Indonesia) given as a single tablet once daily for three consecutive days, two consecutive days, and one day. The randomization code was kept concealed on a passwordprotected personal computer inaccessible to study staff. Stool samples among the three groups were examined on days $7,14,21$, and 28 after the last day treatment administration. Study participants were followed up every day until 1 week for any adverse events, including nausea, vomiting, abdominal pain, diarrhea, headaches, dizziness, fever, fatigue, rash, or insomnia. All children who got adverse events will be treated by doctor staffs of this study.

All analyses were performed on an intention to treat principle. Data were analyzed using intention to treat principle. The efficacy of the three treatment regimens was assessed by using CR and ERR. The cure rate is if no more worm eggs is found after treatment, while ERR is if the number of eggs after treatment is smaller than before treatment. The Chi-square test was used to compare the variable between the treatment group and CR or ERR. The Kruskal Wallis test was used to compare the difference in several eggs among the three groups on days 7, 14, 21, and 28 after the intervention. Data processing was performed using Statistical Package for Social Sciences for Windows (SPSS) version 24.0, 2016 with $p<0.05$ was significance, and $95 \%$ confidence interval.

\section{Results}

A total of 752 participants were screened, and 195 final participants were randomized and received the study drug. 
These 195 participants were grouped in three groups, each consist of 65 participats. The STH prevalence in Batubara, North Sumatera, Indonesia was $41.1 \%$, with the prevalence of $A$. lumbricoides infection was $43.6 \%, T$. trichiura infection was $69.2 \%$, and hookworm infection was $5.1 \%$. The three groups were comparable about age, bodyweight/body height, sex, infection prevalence, and egg load. Distribution of basic characteristics between the third groups at baseline was similar (Table 1).

CR and ERR were dose and species-dependent. The three regimens gave a significantly different $C R$ and ERR for trichuriasis ( $p=0.001$, Chi square test) with the highest efficacy was found in the group receiving three consecutive day albendazole. There was no significant difference in $\mathrm{CR}$ or ERR ascariasis among the three groups ( $p=0.402$, Chi square test) (Table 2). There was not any adverse event attributable to the study among the three groups during the study. T. trichiura egg per gram (EPG) was statistically different among the three groups on day 7, 14, 21, and 28 after treatment $(p<0.001)$ (Table 3$)$.

\section{Discussion}

In our study, the prevalence of $A$. lumbricoides infection was $43.6 \%$, T. trichiura infection was $69.2 \%$, and hookworm infection was $5.1 \%$. Similar results were obtained from a study conducted in Medan in 2007, with $46.52 \%$ of ascariasis infection and $63.37 \%$ of trichuriasis infection, but lower prevalence for hookworm infection $(0.53 \%) .(13)$ This result was caused by the sand and loose soil which is suitable for the breeding of hookworm larvae, and the rule of not wearing shoes in the school environment that increase the risk of hookworm infection through the foot. $(14,15)$

WHO develops a global strategy in controlling STH infections by modern chemotherapy using orally singledose of albendazole $400 \mathrm{mg}$ for adult or children above aged two years. $(2,8)$ However, there is a need to reevaluate its efficacy and safety to continue this intervention.(12)

We found the same efficacy of three consecutive days, two consecutive days, and single-dose of albendazole for treating ascariasis and hookworm infection in this study. Previous studies in Gabon and Yunnan found a significant difference in the efficacy of three consecutive days, two consecutive days and single-dose regimen against hookworm infection. These studies showed that the highest CR was the three consecutive days regimen. $(7,12)$ This difference results may be caused of the lower prevalence of hookworm infections in our study.

In current study, both the three consecutive days and two consecutive days albendazole showed better efficacy than single-dose albendazole for trichuriasis. The highest

Table 1. Basic characteristics of study participants at baseline.

\begin{tabular}{|c|c|c|c|}
\hline \multirow[b]{2}{*}{ Characteristics } & \multicolumn{3}{|c|}{ Duration of Albendazole Administration } \\
\hline & $\begin{array}{l}3 \text { Consecutive Days } \\
\qquad(n=65)\end{array}$ & $\begin{array}{l}2 \text { Consecutive Days } \\
\qquad(\mathrm{n}=65)\end{array}$ & $\begin{array}{l}\text { Single-dose } \\
\qquad(n=65)\end{array}$ \\
\hline Age (year), mean (SD) & $8.2(1.69)$ & $8.9(1.70)$ & $9.2(1.87)$ \\
\hline Body weight/body height (\%) & 90.4 & 91.0 & 94.5 \\
\hline \multicolumn{4}{|l|}{ Sex, n $(\%)$} \\
\hline Male & $33(50.8)$ & $44(67.7)$ & $39(60.0)$ \\
\hline Female & $32(49.2)$ & $21(32.3)$ & $26(40.0)$ \\
\hline \multicolumn{4}{|l|}{ Infection, $\mathrm{n}(\%)$} \\
\hline A.lumbricoides & $31(47.7)$ & $35(53.8)$ & $19(29.2)$ \\
\hline T.trichiura & $39(60.0)$ & $37(56.9)$ & $59(90.8)$ \\
\hline Hookworm & $3(4.6)$ & $3(4.6)$ & $4(6.2)$ \\
\hline \multicolumn{4}{|l|}{ Fecal EPG, median (range) } \\
\hline A.lumbricoides & $1,264(72-21,384)$ & $1,228(48-21,168)$ & $1,344(120-39,880)$ \\
\hline T.trichiura & $120(48-1,968)$ & $216(24-1,032)$ & $216(48-6,624)$ \\
\hline Hookworm & $432(120-1,272)$ & $216(120-1,368)$ & $756(120-2,016)$ \\
\hline \multicolumn{4}{|l|}{ Category of infection, $\mathrm{n}(\%)$} \\
\hline Double infection & $4(6.2)$ & $4(6.2)$ & $13(20)$ \\
\hline Triple infection & $2(3.1)$ & $3(4.6)$ & $2(3.1)$ \\
\hline
\end{tabular}


Table 2. Comparison of efficacy among the three groups on 28 days after treatment.

\begin{tabular}{|c|c|c|c|c|}
\hline \multirow[b]{2}{*}{ Efficacy (\%) } & \multicolumn{3}{|c|}{ Duration of Albendazole Administration } & \multirow[b]{2}{*}{$p^{*}$} \\
\hline & $\begin{array}{l}3 \text { Consecutive Days } \\
\qquad(n=65)\end{array}$ & $\begin{array}{l}2 \text { Consecutive Days } \\
\qquad(n=65)\end{array}$ & $\begin{array}{l}\text { Single-dose } \\
\quad(n=65)\end{array}$ & \\
\hline \multicolumn{5}{|l|}{ Cure rates } \\
\hline Ascariasis & 90.3 & 88.6 & 94.7 & 0.402 \\
\hline Trichuriasis & 79.5 & 70.3 & 32.2 & 0.001 \\
\hline Hookworm infection & 100.0 & 66.7 & 50.0 & 0.362 \\
\hline \multicolumn{5}{|l|}{ Egg reduction rates } \\
\hline A.lumbricoides & 96.8 & 97.2 & 100.0 & 0.058 \\
\hline T.trichiura & 97.4 & 91.9 & 74.6 & 0.001 \\
\hline Hookworm & 100.0 & 100.0 & 100.0 & 0.900 \\
\hline
\end{tabular}

*Chi-square test $(95 \%$ confidence interval).

efficacy was found in the three consecutive days group. The longer the treatment regimen, the patient's adherence tended to get lossen, which will caused the frequency and severity of side effects will be increased.(16)

Similar results study were found in Gabon that the increased efficacy was found by prolonging the duration of albendazole treatment.(12,16) The living place of $T$. trichiura in caecum makes this worm more resistant to the anthelmintic.(17) Repeated-dose of albendazole can prolong the contact time of the drug with the parasite so that it can increases the efficacy.(3) The efficacy was good, eventhough the ERR is high and the CR is low.(18)
On observation of day 7 and 14 after treatment, there was a decreased T. trichiura EPG in our study, followed by an increased T. trichiura EPG on days 21 and 28 after treatment. The decreased T. trichiura EPG occurred due to the treatment effects of anthelmintic. This result is almost same as result of previous study in Uganda, which found the treatment effect of single-dose and three consecutive days albendazole were obtained on seven days observation, and there was an increased T. trichiura EPG on days 14, 21 and 28 after treatment.(3)

WHO recommends the ideal time for observation after giving anthelmintic is 10 to 14 days after treatment. Longer

Table 3. Comparison Fecal EPG among the three groups on days 7, 14, 21 and 28 after treatment.

\begin{tabular}{|c|c|c|c|c|}
\hline \multirow{2}{*}{$\begin{array}{c}\text { Fecal Egg per Gram } \\
\text { After Treatment, } \\
\text { Median (Range) }\end{array}$} & \multicolumn{3}{|c|}{ Duration of Albendazole Administration } & \multirow[b]{2}{*}{$p^{*}$} \\
\hline & $\begin{array}{l}3 \text { Consecutive Days } \\
\qquad(n=65)\end{array}$ & $\begin{array}{l}2 \text { Consecutive Days } \\
\qquad(n=65)\end{array}$ & $\begin{array}{l}\text { Single-dose } \\
\quad(n=65)\end{array}$ & \\
\hline \multicolumn{5}{|l|}{ A.lumbricoides } \\
\hline On day 7 & $0(0-6,312)$ & $0(0-17,048)$ & $0(0-3,384)$ & 0.770 \\
\hline On day 14 & $0(0-6,528)$ & $0(0-1,278)$ & $0(0-840)$ & 0.367 \\
\hline On day 21 & $0(0-10,344)$ & $0(0-1,196)$ & $0(0-628)$ & 0.607 \\
\hline On day 28 & $0(0-11,616)$ & $0(0-1,728)$ & $0(0-504)$ & 0.675 \\
\hline \multicolumn{5}{|l|}{ T.trichiura } \\
\hline On day 7 & $48(0-1,368)$ & $48(0-1,004)$ & $212(0-5,568)$ & 0.001 \\
\hline On day 14 & $0(0-264)$ & $0(0-932)$ & $120(0-3,216)$ & 0.001 \\
\hline On day 21 & $0(0-120)$ & $0(0-2,064)$ & $120(0-2,016)$ & 0.001 \\
\hline On day 28 & $0(0-72)$ & $0(0-2,496)$ & $72(0-1,040)$ & 0.001 \\
\hline \multicolumn{5}{|l|}{ Hookworm } \\
\hline On day 7 & $0(0)$ & $128(0-840)$ & $480(0-840)$ & 0.178 \\
\hline On day 14 & $0(0)$ & $0(0-264)$ & $216(0-648)$ & 0.340 \\
\hline On day 21 & $0(0)$ & $0(0-216)$ & $216(0-648)$ & 0.340 \\
\hline On day 28 & $0(0)$ & $0(0-216)$ & $216(0-648)$ & 0.340 \\
\hline
\end{tabular}

*Kruskal Wallis test. 
observation intervals will produce a lower efficacy rate due to the maturation of immature stage worms.(19) The reincreased T. trichura EPG also indicates that albendazole might inhibit egg production of T. trichiura. However, this inhibition is only transient and will disappear in two weeks. $(20,21)$ A study in Bangladesh found that T. trichiura EPG re-increased on the $10^{\text {th }}$ day of observations after the administration of repeated-dose albendazole for three or five consecutive days.(20) These results support the optimal time for treatment monitoring in this study are on days 7,14 , or 21 , and 28 after anthelmintic administration.

There was no side effect of drug administration among the three regimen albendazole groups in this study. A study in Thailand also found a minimum side effect $(2.4 \%)$ with the administration of albendazole 400 for seven consecutive days, that was headaches, dizziness, and insomnia.(22) The study in Langkat district, Sumatera Utara, Indonesia found that the side effects of five and seven consecutive days albendazole administration were nausea, dizziness, dry mouth, and diarrhea.(16)

Our study is useful as an evaluation of the government program for giving single-dose albendazole to eliminate the three STH infections in Indonesia. This is the first study to compare the efficacy among three consecutive days, two consecutive days and single-dose of albendazole against the three types of STH infections in Indonesia, so hopefully it can increase our knowledge of a better albendazole regimen to improve children's health. The limitations of our study was the diagnosis of STH infection only through a single Kato-Katz examination. The accuracy of the Kato-Katz technique in detecting STH infection is strongly influenced by variations in the excretion of worm eggs from day to day and unevenly spread of egg worm in the feces. Some researchers suggest for examining two consecutive days of stool specimens to improve accuracy.(23)

\section{Conclusion}

Three consecutive days and two consecutive days albendazole have better efficacy than single-dose albendazole for trichuriasis, but not for ascariasis or hookworm infection. Single-dose albendazole is effective against ascariasis and hookworm infections, while two consecutive days albendazole may be a better choice for treating trichuriasis. Stool examination using the Kato-Katz method should be done before anthelmintic administration to get the appropriate regimen according to the type of STH infection.

\section{References}

1. Bethony J, Brooker S, Albonico M, Geiger SM, Loukas A, Diemert D, et al. Soil-transmitted helminth infections: ascariasis, trichuriasis, and hookworm. Lancet. 2006; 367:1521-32.

2. World Health Organization. Soil-transmitted helminthiases, eliminating soil-transmitted helminthiases as a public health problem in children: progress report 2001-2010 and strategic plan 2011-2020. Geneva: WHO Press; 2012.

3. Namwanje H, Kabatereine NB, Olsen A. Efficacy of single and double doses of albendazole and mebendazole alone and combination in the treatment of Trichuris trichiura in school-age children in Uganda. Trans R Soc Trop Med Hyg. 2011; 105: 586-90.

4. Hughes S, Kelly P. Interactions of malnutrition and immune impairment, with specific reference to immunity against parasites. Parasite Immunol. 2006; 28: 577-88.

5. Keiser J, Utzinger J. Efficacy of current drugs against soil-transmitted helminth infections: systematic review and meta-analysis. JAMA. 2008; 299: 1937-48.

6. World Health Organization. Helminth control in school-age children, a guide for managers of control programmes. 2nd ed. Geneva: WHO Press; 2011.

7. Steinmann P, Utzinger J, Du ZW, Jiang JY, Chen JX, Hattendorf $\mathrm{J}$, et al. Efficacy of single-dose and triple-dose albendazole and mebendazole against soil-transmitted helminths and taenia spp: a randomized controlled trial. PLoS One. 2011; 6: e25003. doi: 10.1371/journal.pone.0025003.

8. Kementerian Kesehatan RI, Direktorat Jenderal P2PL. Pedoman pengendalian kecacingan. Jakarta: Kementerian Kesehatan RI; 2012 .

9. Kementerian Kesehatan RI. Rencana aksi program pengendalian penyakit dan penyehatan lingkungan tahun 2015. Jakarta: Kementerian Kesehatan RI; 2015.

10. Novianty S, Dimyati Y, Pasaribu S, Pasaribu AP. Risk factors for soiltransmitted helminthiasis in preschool children living in farmland, North Sumatera, Indonesia. J Trop Med. 2018; 3: 6706413. doi: $10.1155 / 2018 / 6706413$.

11. Subahar R, Mahfudin H, Ismid IS. Pendidikan dan pengetahuan orangtua murid sehubungan dengan upaya pemberantasan penyakit cacing usus di Duren Sawit Jakarta Timur. Majalah Kesehatan Masyarakat Indonesia. 1995: 1: 4-21.

12. Adegnika AA, Zinsou JF, Issifou $\mathrm{S}$, Ateba-Ngoa U, Kassa $\mathrm{RF}$, Feugap EN, et al. Randomized, controlled, assessor-blind clinical trial to assess the efficacy of single-versus repeated-dose albendazole to treat Ascaris lumbricoides, Trichuris trichiura, and hookworm infection. Antimicrob Agents Chemother. 2014; 58: 2535-40.

13. Yunus R. Keefektifan albendazole pemberian sekali sehari selama 1, 2, dan 3 hari dalam menanggulangi infeksi Trichuris trichiura pada anak sekolah dasar di kecamatan Medan Tembung [Thesis]. Medan: Universitas Sumatera Utara; 2008.

14. Suriptiastuti. Infeksi soil-transmitted helminth: ascariasis, trichuriasis dan cacing tambang. UnivMed. 2006; 25: 84-93.

15. Prasetyo RH. Buku ajar parasitologi kedokteran parasit usus. Jakarta: Sagung Seto; 2013.

16. Lubis AD, Pasaribu S, Ali M, Lubis M. Effect of length of albendazole treatment against Trichuris trichiura infection. Paediatr Indones. 2013; 53: 245-9.

17. Soedarto. Buku ajar parasitologi kedokteran. Jakarta: Sagung Seto; 2011. 
18. Horton J. The efficacy of anthelmintics: past, present, future. In: Crompton DWT, Montresor A, Nesheim MC, Savioli L, editors. Controlling disease due to helminth infections. Geneva: WHO; 2003.

19. Vercruysse J, Albonico M, Behnke J, Kotze A, McCarthy J, Prichard $\mathrm{R}$, et al. Monitoring anthelmintics efficacy for soil-transmitted helminths (STH). Geneva: WHO; 2008.

20. Hall A, Nahar Q. Albendazole and infections with Ascaris lumbricoides and Trichuris trichiura in children in Bangladesh. Trans R Soc Trop Med Hyg. 1994: 88: 110-2.

21. Olsen A, Namwanje H. Nejsum P, Roepstroff A, Thamsborg SM. Albendazole and mebendazole have low efficacy against Trichuris trichiura in school-age children in Kabale District, Uganda. Trans R Soc Trop Med Hyg. 2009; 103: 443-6.

22. Sirivichayakul C, Pojjaroen-anant C, Wisetsing P, Praevant R, Chanthavanich P, Limkittikul K. The effectiveness of 3, 5, or 7 days of albendazole for the treatment of Trichuris trichiura infection. Ann Trop Med Parasitol. 2003; 97: 847-53.

23. Tarafder MR, Carabin H, Joseph L, Balolong E, Olveda R, McGarvey ST. Estimating the sensitivity and specificity of katokatz stool examination technique for detection of hookworm, Ascaris lumbricoides and Trichuris trichiura infections in human in the absence of a gold standard. Int J Parasitol. 2010; 40: 399404. 